\title{
Glacier Image Velocimetry: an open-source toolbox for easy and rapid calculation of high-resolution glacier velocity fields
}

\author{
Maximillian Van Wyk de Vries ${ }^{1,2}$ and Andrew D. Wickert ${ }^{1,2}$ \\ ${ }^{1}$ Department of Earth \& Environmental Sciences, University of Minnesota, Minneapolis, MN, USA \\ ${ }^{2}$ Saint Anthony Falls Laboratory, University of Minnesota, Minneapolis, MN, USA \\ Correspondence: Maximillian Van Wyk de Vries (vanwy048@umn.edu)
}

Received: 17 July 2020 - Discussion started: 31 July 2020

Revised: 20 March 2021 - Accepted: 23 March 2021 - Published: 28 April 2021

\begin{abstract}
We present Glacier Image Velocimetry (GIV), an open-source and easy-to-use software toolkit for rapidly calculating high-spatial-resolution glacier velocity fields. Glacier ice velocity fields reveal flow dynamics, ice-flux changes, and (with additional data and modelling) ice thickness. Obtaining glacier velocity measurements over wide areas with field techniques is labour intensive and often associated with safety risks. The recent increased availability of high-resolution, short-repeat-time optical imagery allows us to obtain ice displacement fields using "feature tracking" based on matching persistent irregularities on the ice surface between images and hence, surface velocity over time. GIV is fully parallelized and automatically detects, filters, and extracts velocities from large datasets of images. Through this coupled toolchain and an easy-to-use GUI, GIV can rapidly analyse hundreds to thousands of image pairs on a laptop or desktop computer. We present four example applications of the GIV toolkit in which we complement a glaciology field campaign (Glaciar Perito Moreno, Argentina) and calculate the velocity fields of small mid-latitude (Glacier d'Argentière, France) and tropical glaciers (Volcán Chimborazo, Ecuador), as well as very large glaciers (Vavilov Ice Cap, Russia). Fully commented MATLAB code and a standalone app for GIV are available from GitHub and Zenodo (see https://doi.org/10.5281/zenodo.4624831, Van Wyk de Vries, 2021a).
\end{abstract}

\section{Introduction}

Satellite imagery revolutionized our ability to study changes in glacier extent, volume, and surface velocities and is an effective tool for communicating these changes to the broader public (Scambos et al., 1992; Rignot et al., 2011; Heid and Kääb, 2012a; Stocker et al., 2013; Howat et al., 2019). Glacier velocity measurements enable scientists to map glacier divides and drainage basins (Davies and Glasser, 2012; Pfeffer et al., 2014; Mouginot and Rignot, 2015), track changes in surface melt production and accumulation (Mote, 2007; Sneed and Hamilton, 2007), and address key questions about ice dynamics and the future of glaciers under a changing climate (Stearns et al., 2008; van de Wal et al., 2008; Rignot et al., 2011; Willis et al., 2018; Millan et al., 2019; Altena et al., 2019). Even the earliest glaciologists identified that glaciers may flow as viscous fluids (Forbes, 1840, 1846; Bottomley, 1879; Nye, 1952) and later that glacier surface motions reflect a complex interplay between internal deformation, basal sliding, and deformation of subglacial sediments (Deeley and Parr, 1914; Weertman, 1957; Kamb and LaChapelle, 1964; Nye, 1970; Fowler, 2010). Such changes reflect a combination of glacier mass balance and basal conditions - including time-varying hydrology - both of which may respond to climate. Widespread measurement of glacier surface velocities, a key constraint on glacier dynamics, has however only become possible with the advent of satellitebased remote sensing (e.g. Bindschadler and Scambos, 1991; Scambos et al., 1992).

Deriving glacier velocities from satellite imagery is possible through an image analysis technique known as "feature tracking", "image cross correlation", or "particle image ve- 
locimetry" (PIV). The latter term, particle image velocimetry, describes a well-established technique in fluid dynamics typically involving the use of a high-speed digital camera to track the motion of tracers within a fluid in a laboratory setting (Buchhave, 1992; Grant, 1997; Raffel et al., 2018). These ideas were first carried over to the field of glaciology by Bindschadler and Scambos (1991) and Scambos et al. (1992) to evaluate the flow velocity of a portion of an Antarctic ice stream. Since that time, the increasing abundance and availability of imagery has facilitated the expanded use of feature-tracking-based velocimetry techniques. With the release of the full Landsat data archive and launch of Sentinel$2,10-30 \mathrm{~m}$ pixel resolution imagery of any given location is now available at sub-weekly repeat coverage intervals. A number of studies apply this exceptional archive to map velocity fields across the major ice sheets, as well as those of many glaciers around the world (Gardner et al., 2018; Millan, 2019).

Prior to the advent of remote sensing, spatially distributed measurements of glacier flow velocities required lengthy field campaigns (Meier and Tangborn, 1965; Hooke et al., 1989; Chadwell, 1999; Mair et al., 2003). Nowadays full 2D flow-velocity maps may be readily calculated from a variety of optical- and radar-based satellite imagery (Heid and Kääb, 2012b; Fahnestock et al., 2016). For this toolbox we focus on optical imagery products due to their ease of access, limited need for pre-processing, and high spatial and temporal resolution (Drusch et al., 2012; Heid and Kääb, 2012b, a; Kääb et al., 2016; Darji et al., 2018).

A number of tools exist to derive displacements from imagery, as partially reviewed by Heid and Kääb (2012a), Jawak et al. (2018), and Darji et al. (2018). These include CARST (Cryosphere and Remote Sensing Toolkit; Willis et al., 2018), COSI-corr (Co-registration of Optically Sensed Images and Correlation; Leprince et al., 2007b), AutoRIFT (Autonomous Repeat Image Feature Tracking; Gardner et al., 2018), ImGRAFT (Image Georectification and Feature Tracking; Messerli and Grinsted, 2015), and SenDiT (the Sentinel-2 Displacement Toolbox; Nagy and Andreassen, 2019; Nagy et al., 2019). CARST contains a mixture of Python and Bash scripts used to monitor changes in glaciers and includes feature-tracking and ice-elevationchange-monitoring tools (Willis et al., 2018; Zheng et al., 2018, 2019a). COSI-Corr is a flexible co-registration and feature-tracking tool written in IDL, implemented in the ENVI GIS package, and initially used for measuring coseismic deformation. Auto-RIFT is a Python-based featuretracking algorithm (Gardner et al., 2018). ImGRAFT is a MATLAB-based toolbox for georectifying and feature tracking of ground-based imagery and may also be used on satellite imagery. SenDiT provides a platform to automatically download and generate velocity maps based on Sentinel-2 data using a Python interface with bindings to the C- and Fortran-based imcorr toolbox (Scambos et al., 1992) for feature-tracking calculations. In addition, near-global ice ve- locity maps are calculated in near real time from Landsat and other freely available satellite data sources: GoLIVE using PyCorr (Scambos, 2016) and ITS_LIVE using Auto-RIFT (Gardner et al., 2020).

Table 1 presents a non-exhaustive list of feature-tracking software packages. In some circumstances, GIV will not be the most suitable feature-tracking tool depending on the user's requirements. For example, users who need to manually perform prior image co-registration (e.g. with airphotos) may wish to use the built-in workflow in COSI-Corr. The objective of the Glacier Image Velocimetry (GIV) toolbox presented here is not to compete with or replace these other tools. Rather, GIV aims to provide an easy-to-use, flexible, and robust alternative. GIV may be used to derive high spatial and temporal resolution surface-velocity maps of glaciers of all scales. The following section will run through the basics of the image-feature-tracking techniques and advances built into GIV.

\section{Methods and model setup}

The fundamental idea of feature tracking is based on techniques used to co-register images: the properties of two images are compared in order to identify the best-fit location of one image within the other (Scambos et al., 1992; Thielicke and Stamhuis, 2014; Messerli and Grinsted, 2015). In feature tracking, including in GIV, individual images are divided into a grid of smaller images (referred to as "chips"). We compare each individual chip from the first image (I1) to a surrounding portion within a second image (I2) and find the best matching portion of I2. If no displacement has occurred between the two images, the best-fitting portion of I 2 will have the same location as the original chip on I1 (excluding any georeferencing or distortion-related errors). However, if any motion has occurred between the two images, the corresponding best matching chip within $\mathrm{I} 2$ will be displaced relative the original location within I1. We may then determine the bulk displacement in pixels between the original I1 chip and best matching I 2 chip. The correlation coefficients between the original chip and surrounding area within I2 are also calculated. This allows a Gaussian curve to be fit to this grid in order to determine the peak location at sub-pixel accuracy. Repeating this routine for every chip within the original image allows a 2D surface velocity field to be derived.

While initially developed for use in laboratory-based fluid dynamics, the camera, lighting, and tracer-particle conditions were all closely constrained (Grant, 1997; Raffel et al., 2018). On glaciers, features change over time as crevasses open and close, snow drifts, and ablation exposes new surfaces. In addition, the satellite may acquire imagery from slightly different locations and angles with each pass, and lighting conditions depend strongly on the time of day and year, as well as degree of shadowing and local weather conditions (Berthier et al., 2005; Kääb et al., 2016). This com- 
Table 1. Non-exhaustive list of codes and toolboxes that may be used for feature tracking and associated references. For availability, $1=$ fully available, 2 = available but relies on commercial software, and $3=$ not available. A spreadsheet with download links is available in the Supplement.

\begin{tabular}{|c|c|c|c|}
\hline Toolbox & Source & Summary & Availability \\
\hline Auto-RIFT & Gardner et al. (2018) & $\begin{array}{l}\text { Python dense feature-tracking package for calculating displacement } \\
\text { from optical or radar imagery. Used for calculating the ITS_LIVE } \\
\text { global velocity dataset. }\end{array}$ & 1 \\
\hline CARST & Zheng et al. (2019a) & $\begin{array}{l}\text { Python and bash scripts for feature tracking and ice elevation } \\
\text { change analysis. }\end{array}$ & 1 \\
\hline CIAS & Kääb and Vollmer (2000) & $\begin{array}{l}\text { IDL-based correlation software to compute offsets between two im- } \\
\text { ages. }\end{array}$ & 1 \\
\hline Cosi-Corr & Leprince et al. (2007a) & $\begin{array}{l}\text { IDL/ENVI-based package for image co-registration and displace- } \\
\text { ment mapping. }\end{array}$ & 2 \\
\hline EMT & Schwalbe and Maas (2017) & $\begin{array}{l}\text { Workflow for analysis and feature tracking of time-lapse ground- } \\
\text { based imagery. }\end{array}$ & 1 \\
\hline GIV & This study. & GUI-based feature-tracking toolbox for glaciology. & 1 \\
\hline fourDvel & Minchew et al. (2017) & $\begin{array}{l}\text { Fortran routine for calculation of 3D velocity fields from geolocated } \\
\text { displacement data. }\end{array}$ & 1 \\
\hline ImCorr & Scambos et al. (1992) & $\begin{array}{l}\mathrm{C} \text { and Fortran package for dense feature tracking of satellite or air- } \\
\text { photo imagery. }\end{array}$ & 1 \\
\hline ImGRAFT & Messerli and Grinsted (2015) & $\begin{array}{l}\text { MATLAB-based package for georectification of ground-based im- } \\
\text { agery and feature tracking. }\end{array}$ & 2 \\
\hline MatPIV & Sveen (2004) & $\begin{array}{l}\text { MATLAB-based toolbox for pattern matching and particle image } \\
\text { velocimetry (PIV). }\end{array}$ & 2 \\
\hline PIVlab & Thielicke and Stamhuis (2014) & GUI-based MATLAB PIV toolbox. & 2 \\
\hline Pointcatcher & James et al. (2016) & $\begin{array}{l}\text { MATLAB-based toolbox for facilitating manual feature tracking in } \\
\text { image time series. }\end{array}$ & 2 \\
\hline PyCorr & Fahnestock et al. (2016) & $\begin{array}{l}\text { Python-based feature-tracking toolbox. Used for calculating the Go- } \\
\text { LIVE global velocity dataset. }\end{array}$ & 3 \\
\hline PyTrx & How et al. (2020) & $\begin{array}{l}\text { Python toolbox created for calculating displacements from oblique } \\
\text { images and time-lapse image series. }\end{array}$ & 1 \\
\hline SendIT & Nagy et al. (2019) & $\begin{array}{l}\text { Flexible processing toolbox for retrieval of glacier surface veloci- } \\
\text { ties, based on ImCorr. }\end{array}$ & 1 \\
\hline vmap & Shean (2019) & $\begin{array}{l}\text { Ames-Stereo-Pipeline-based image correlator for velocity map gen- } \\
\text { eration. }\end{array}$ & 1 \\
\hline
\end{tabular}

plexity raises additional problems in the use of this technique for deriving glacier velocities and makes it entirely unusable in some cases (e.g. images too far spaced in time relative to the speed of the glacier for image pairs to retain any coherence). These problems can be mitigated though a combination of image pre-filtering, comparison between adjacent velocity maps, and outlier filtering. We also refer readers to Sects. 2 and 4 of Altena (2018) for a detailed discussion on these topics. The Glacier Image Velocimetry toolbox makes use of these methods, with a particular emphasis on noise reduction in individual velocity map outputs through the use of large datasets. Figure 1 presents the overall model setup and order of operations.

\subsection{Model pre-processing}

Prior to running the feature-tracking algorithms, the satellite images are first loaded into the workspace and filtered. The user interface will prompt the user to enter the coordinates of the images (minimum and maximum latitude and longitude) and to select a given folder in which the images are stored. These images can be .png, .jpg, or .geotiff files of the 


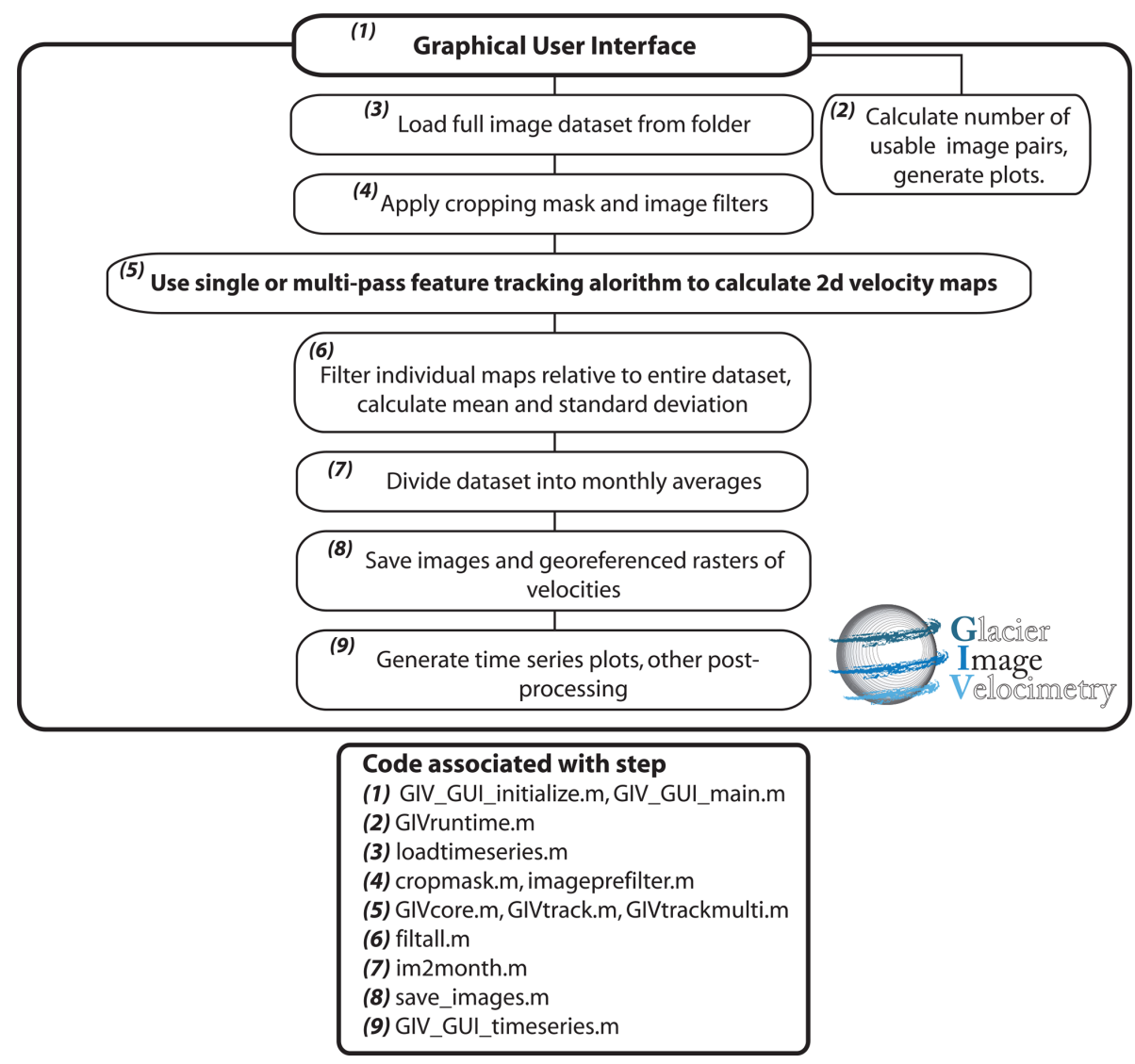

Figure 1. Flowchart describing the Glacier Image Velocimetry toolbox design. Names of the code files associated with each step are given for reference (and are available in the linked Zenodo repository). The feature-tracking step is shown in bold. Note that the source code is open source but that accessing it is not necessary for running GIV. Users may enter all parameter options into fields in the user interface, with subsequent steps automatically performed by the toolbox.

area, with each file name being the date of image acquisition (in yyyymmdd format). In the case of a GeoTIFF input, GIV will automatically load the geographic information from the input. GIV will then extract the dates from the file names, calculate time between images, and load the raw image data into an array for further processing. The user also inputs a modified image with glaciers of interest converted to pure white (RGB 255, 255, 255). This image is loaded by GIV and converted into a binary mask with areas within (1) and outside (0) the computational region. The size and resolution of images are also automatically calculated and resampled to a common resolution such that images from different satellites may be combined in the same dataset.

Following this, GIV filters the images according to userdefined settings. GIV includes a range of filters in order to reduce the effect of unwanted noise (e.g. clouds and shadows) and emphasize trackable features (e.g. crevasses, snowdrifts, supraglacial debris). In particular we include highpass, Sobel, and Laplacian filter options to emphasize shortwavelength features and edges, as well as intensity-capping and contrast-limited histogram-equalization filters to im- prove image contrast (Sveen, 2004; Thielicke and Stamhuis, 2014; Gardner et al., 2018). We also include a variation of the orientation filter (Fitch et al., 2002) named "near anisotropic orientation filter" (NAOF). We define this filter as follows:

$\mathbf{I}_{\mathrm{f}}=\sum_{i=1}^{4} \cos \left[\arctan 2\left(\mathbf{I}_{\mathrm{o}} \cdot \alpha_{i}, \mathbf{I}_{\mathrm{o}} \cdot R\left[\alpha_{i}\right]\right)\right]$,

with $\mathbf{I}_{\mathbf{f}}$ being the filtered image and $\mathbf{I}_{\mathrm{o}}$ the original image, $\alpha$ representing four different convolution matrices oriented at $45^{\circ}$ from each other using the eight adjacent pixels, $\arctan 2(x, y)$ representing the four-quadrant arctangent (also called the two-argument arctangent), $x \times y$ representing a $2 \mathrm{D}$ matrix convolution, and $R[x]$ representing a $90^{\circ}$ matrix rotation. This filter works by summing differently angled orientation filters together in order to recover a "pseudo-feature" with the same location as the original feature but with an increased contrast between the feature and the background and homogenized magnitude (Fitch et al., 2002; Kobayashi and Otsu, 2008). Information on absolute pixel colour magnitude is discarded, with only information on colour gradients preserved. A similar result may be obtained by convolv- 


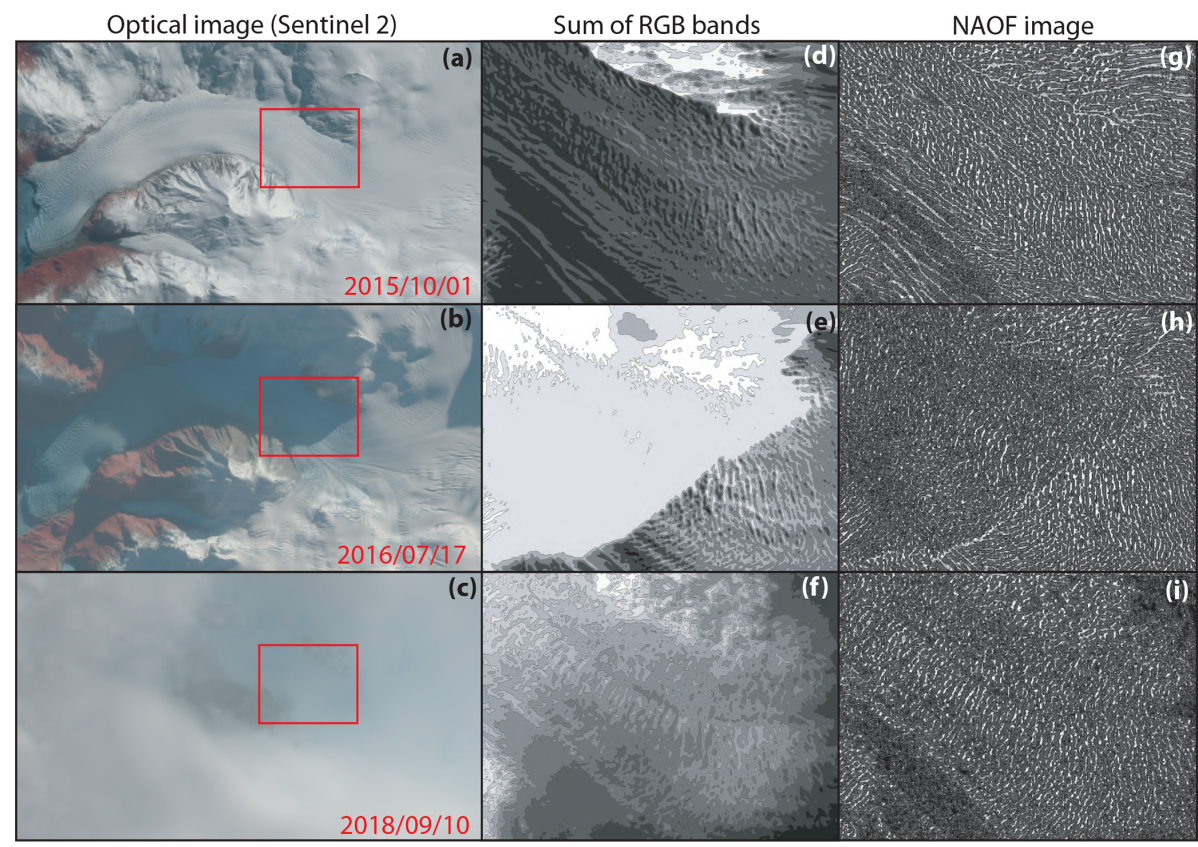

Figure 2. Comparison between raw optical images, band-summed images, and NAOF-filtered images for a clear image (a, d, $\mathbf{g})$, a heavily shadowed image $(\mathbf{b}, \mathbf{e}, \mathbf{h})$, and a cloudy image $(\mathbf{c}, \mathbf{f}, \mathbf{i})$ of Amalia glacier, Patagonia $\left(-50.92^{\circ} \mathrm{S},-73.56^{\circ} \mathrm{W}\right)$. Note how despite the complexity, the NAOF images recover a clear and easily traceable feature pattern on the surface of the glacier that is suitable for obtaining velocities. The shadow line leaves an artefact in (h) but is a marked improvement on the lack of features in the shaded area in (e). Images from Sentinel-2.

ing the original image with a single convolution matrix summing the four directional filters, but this normalizes all features to a single magnitude and results in a larger number of false matches. The NAOF has the advantages of (a) strongly increasing the contrast between features and background; (b) removing contrast differences between clouded, shadowed, and clear areas; and (c) preserving feature location and uniqueness. Figure 2 shows examples of how this filter is able to recover features from challenging images. Many glaciated areas remain cloud covered and shadowed for much of the year, so being able to recover partial velocity fields from these images can greatly increase the size of potential datasets. Note that no amount of filtering can improve certain images, such as those in which cloud cover is too thick for the glacier surface to be visible. An evaluation of the quality of velocity maps derived from different image filters is provided in the Supplement (Figs. S1-S16 in the Supplement). These show that NAOF, contrast-limited histogram equalization, and high-pass filtering provide a major improvement over raw imagery.

\subsection{Velocity calculations}

\subsubsection{Frequency domain matching}

The central part of any feature-tracking code involves matching a small region of one image (chip) with a surrounding region of a second image ("search area"). The chip is matched to the search area through $2 \mathrm{D}$ cross correlation, which may be performed in the spatial or frequency domain (Thielicke and Stamhuis, 2014; Altena, 2018). Matching in the spatial domain ("normalized cross correlation") may better account for feature distortion or shear and may have a higher accuracy (Thielicke and Stamhuis, 2014). Frequency domain methods ("frequency cross correlation") generally benefit from a greater computational efficiency as the correlation matrix is calculated across the whole domain in one operation. We implement frequency domain matching in GIV as feature distortion is minimal in most glaciers and it has been found to perform well in prior studies (e.g. Heid and Kääb, 2012a). We refer readers to Thielicke and Stamhuis (2014) and Sect. 4 of Altena (2018) for more details on these topics.

Frequency cross correlation involves calculating the correlation between the chip and search area in the frequency domain. This is done by converting both the chip and search area to the frequency domain using a fast Fourier transform (FFT), calculating the pointwise product between these two matrices, and converting the resulting similarity matrix back to the spatial domain with an inverse FFT. This step is repeated on each chip within the original image and is the most computationally expensive of the entire process.

GIV is written in MATLAB. Despite being a high-level interpreted programming language, MATLAB performs FFT calculations using pre-compiled $\mathrm{C}$ and Fortran bindings for the FFTW library (Frigo and Johnson, 1998, 2005). Due to this being the rate-limiting step in feature-tracking calculations ( $>90 \%$ of computation time in most cases), such code 

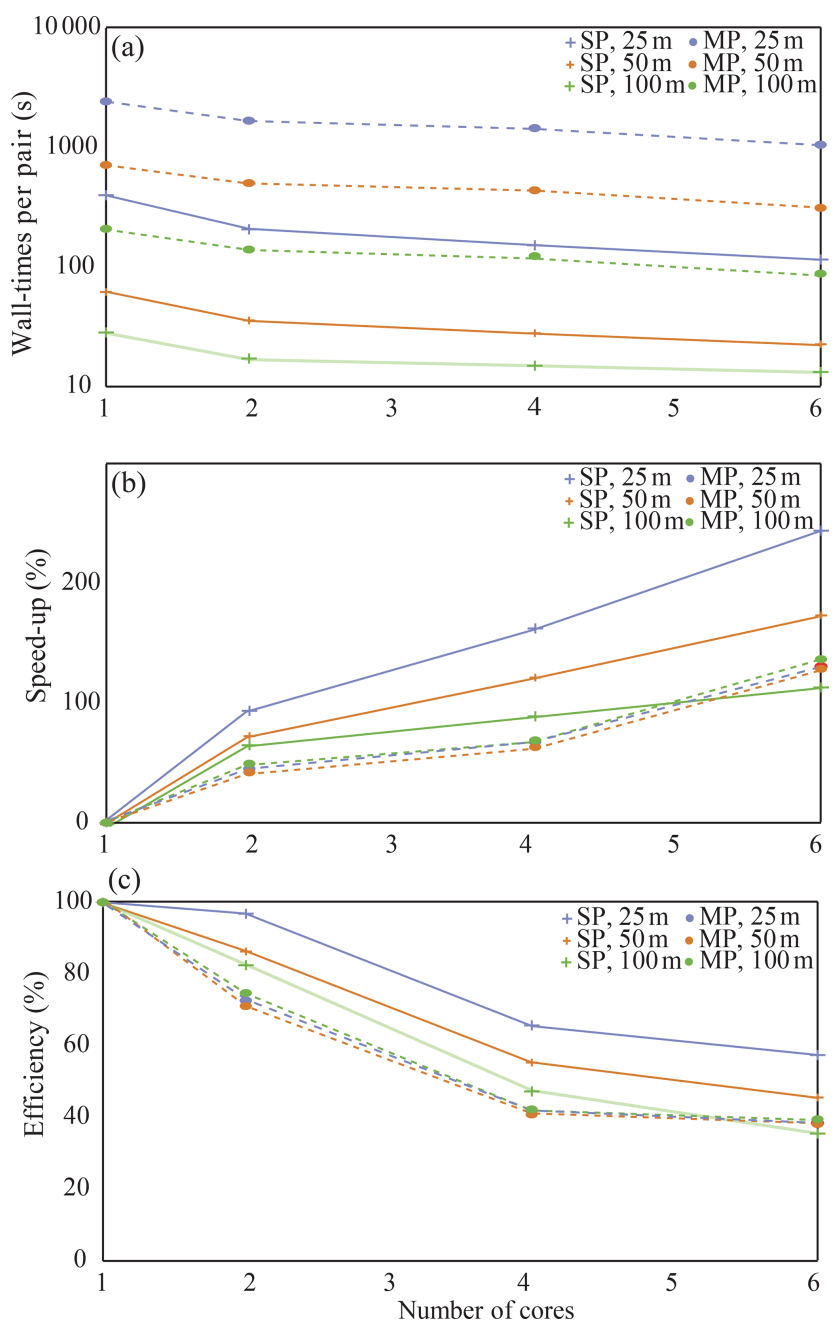

Figure 3. $\mathrm{MP}=$ multi-pass; $\mathrm{SP}=$ single-pass. Test conducted on a 12-image dataset of $10 \mathrm{~m}$ resolution, 1.7 million pixel images of Amalia Glacier, Chile, using a Dell XPS 15 laptop $(2 \times 16 \mathrm{~GB}$ DDR4 $2666 \mathrm{MHz}$ memory, 6-core Intel i7-8750H $2.20 \mathrm{GHz}$ processor). In all cases, parallelization decreases runtime, and going from one to two cores improves runtime by $1.4-1.9 \times$. Fine-resolution multi-pass runs usually yield the best velocity fields, and (b) shows that these benefit from the largest speed-up when parallelized.

may be written in MATLAB with few performance issues relative to other programming languages.

\subsubsection{Parallel computing}

As the feature-tracking correlation between two images inherently requires a large number of FFT and inverse FFT (IFFT) operations, this step has limited potential for further optimization. Computation time may instead be decreased by deriving displacement fields from different image pairs in parallel rather than in series. This requires a slightly different code design. First, GIV detects the number of physical cores on the user's computer and starts a parallel pool; alter- natively, users may start their own parallel pool with a chosen number of cores. It then decomposes the full sequence of image pairs into sub-sequences, each containing a number of image pairs equal to the number of cores. Finally, displacements are calculated in parallel on the image pairs within each sub-sequence (each on a different core in the computer). Figure 3 shows the increase in computation speed with number of cores used in different scenarios. This enables large datasets to be processed more rapidly, even on standard laptop and desktop computers.

\subsubsection{Single- and multi-pass approaches}

Displacements may be derived from an image pair either with a single pass across the images or with multiple passes with gradually reducing window sizes (Thielicke and Stamhuis, 2014; Raffel et al., 2018). Single-pass methods generally have the advantage of generally being faster at coarse resolutions and are less at risk of smearing one erroneous value over a larger area. Multi-pass methods update displacement estimates over multiple iterations, refining initial coarse-window-size displacement calculations using progressively smaller window sizes. Multi-pass methods combine the advantages of better feature matching at large window sizes with the higher spatial resolution of small window sizes. Both methods are integrated into GIV, with a singlepass method based on ImGRAFT (Messerli and Grinsted, 2015) and a three-iteration multi-pass algorithm modified from MatPIV (Sveen, 2004). Both functions have been tested in a number of previous studies, with MatPIV being used extensively in fluid-dynamics research (e.g. Sveen and Cowen, 2004; Sveen, 2004; Lee et al., 2017; Oertel and Süfke, 2020). An experiment evaluating the difference between a normalized cross-correlation algorithm and the multi-pass frequency domain cross correlation in GIV is given in the Supplement. We find that the multi-pass frequency domain algorithm produces velocity maps with a higher signal to noise ratio than the normalized cross-correlation algorithm across test scenarios with a range of cloud cover.

\subsubsection{Non-consecutive images}

GIV may also calculate velocity maps for pairs of nonconsecutive images, which we refer to as "temporal oversampling", resulting in much larger final datasets. The user inputs maximum and minimum temporal separations for image pairs, and GIV extracts all suitable pairs, including those that are not consecutive. For a dataset of $n$ images, this theoretically enables a total of $\left(n^{2}-n\right) / 2$ image pairs. For example, this would produce 19,900 image pairs from a 200 -satelliteimage time series. For heavily clouded datasets this also has the advantage of increasing the likelihood of forming cloudfree image pairs. 

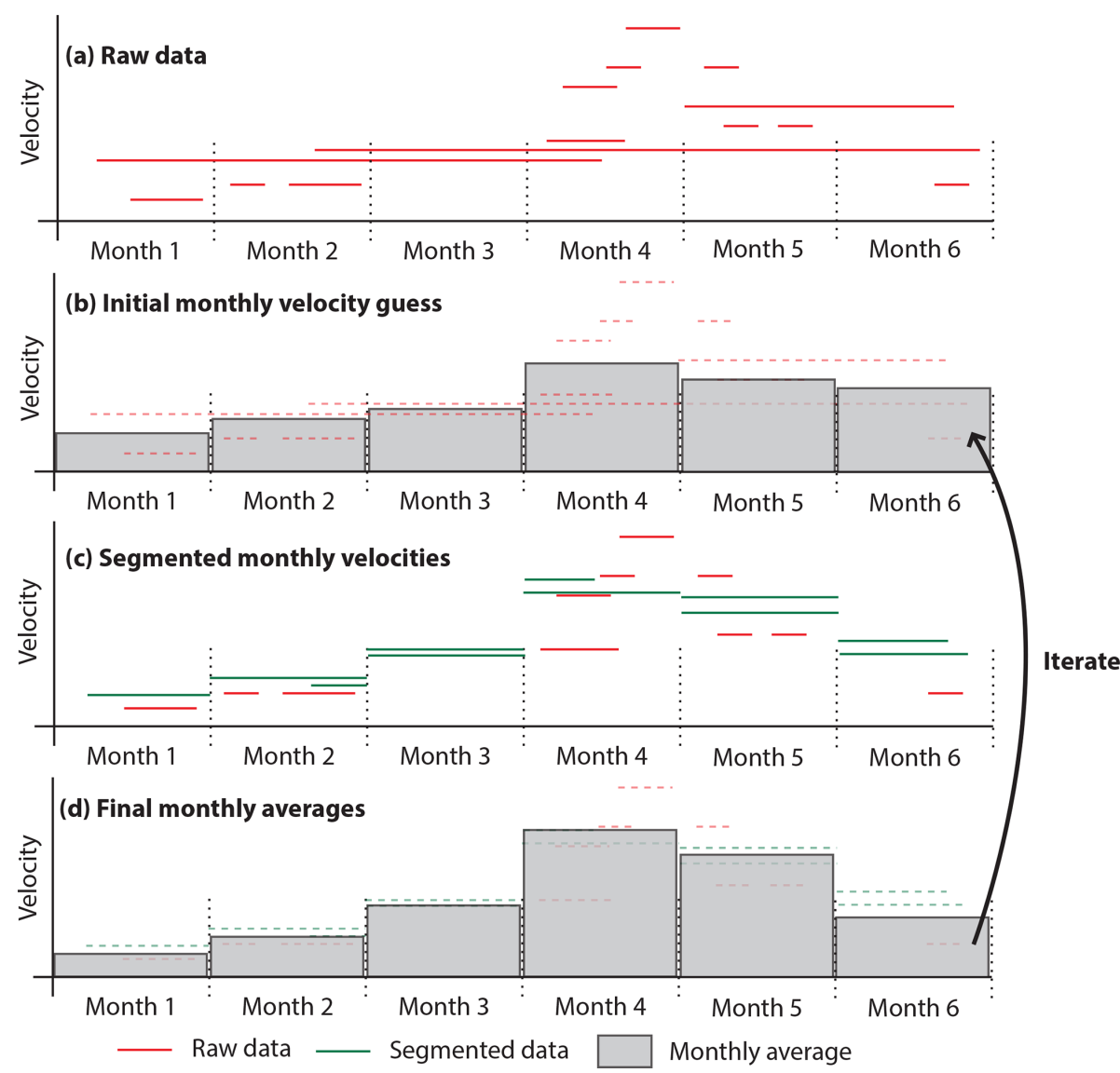

Figure 4. Schematic description of the techniques used to derive monthly velocities. The raw data (a) are combined in a weighted average to make an initial guess of monthly averages (b). The monthly averages are then used to segment longer time period velocity maps into their different monthly contributions (c). These are used to recalculate the monthly averages (d). Finally, GIV iterates over steps (b-d) for a number of times (e.g. 10) provided by user inputs. Note that an estimate may be made for the average velocity in "Month 3" despite this month having no imagery available.

\subsubsection{Velocity map filtering and improvement}

Apart from some scenarios and positions, such as surges, spring speed-ups, and the margins of ice streams, glacier velocity gradients vary gradually in both space (low lateral velocity gradients) and time (low acceleration). Therefore, the accuracy of individual velocity measurements can be evaluated by comparing them to their immediate neighbours in both space and time. Sudden jumps in space or time most likely represent erroneous velocities due to mismatches within the feature-tracking algorithm. This property is used in the GIV toolbox to improve the final velocity maps through the following workflow.

Firstly, GIV filters each individual velocity map through user-prescribed limits on velocity and flow direction, as well as outlier detection functions. This finds values that differ by more than $50 \%$ from their immediate neighbours (four surrounding cells) and $200 \%$ from the mean of their larger local area (25 surrounding cells), removes these outlier values, and interpolates across these now-empty pixels using the re- maining values. Secondly, GIV calculates the mean, standard deviation, and median, minimum, and maximum velocities through time at each grid cell in the dataset. It then compares each individual value to the mean value at that location for the entire dataset. Any values more than 1.5 standard deviations away from this mean are considered outliers. This process is carried out for the $x$ and $y$ components of velocity and flow-speed and flow-direction grids, and only values within the threshold for all velocity and flow direction components are conserved. This provides an additional check as erroneous values are unlikely to coincidentally match both the velocity and flow direction. Finally, the entire dataset may be smoothed and interpolated in space or time and space according to the user's choices. This allows missing values at one time step to be linearly infilled from neighbouring times. In addition, the displacement of each image pair may be normalized to the displacement of a user-defined stable ground mask to correct for systematic georeferencing errors. 


\subsubsection{Temporal resampling}

Variable satellite repeat intervals and the exclusion of entirely clouded or otherwise unusable images lead to unevenly spaced velocity time series that are more difficult to interpret. In order to reduce this challenge, GIV includes a function that automatically averages the data and resamples it to monthly intervals. This is easy when all individual velocity maps cover periods of less than 1 month and do not overlap between months but become more complex when they do. In many cases, image pairs with the shortest lag times $(<7-$ $10 \mathrm{~d})$ are excluded because displacement over such a short time may be obscured by offsets due to distortion and/or georeferencing errors. For the slowest-moving glaciers, this lower bound may be extended to several weeks or months. Lag times as long as the available imagery time series may be used so long as the surface of the glacier retains coherence in the image pairs.

GIV can determine monthly values by averaging across all image pairs that overlap with a given month. However, this produces an artificially smoothed dataset due to the influence of velocities measured across the boundaries of months. In order to make use of longer lag-time pairs, we develop an iterative strategy for calculating monthly values. In the first place, GIV takes a weighted mean of all velocities covering that month to make an initial guess at monthly velocities. The weighting parameter is determined by the proportion of the individual map contained within a given month. For instance, a velocity entirely within 1 month will be weighted 1 , while a velocity spread evenly over 4 months will be weighted 0.25 . This initial estimate is then used to iterate between monthly averages and raw data values, with raw values covering more than 1 month split into monthly values by subtracting the previous iteration's estimate of monthly averages from them (Fig. 4). This procedure may extract average monthly velocities even for months lacking any images. Outlier detection and maximum velocity filters are implemented based on user-provided maximum velocity and comparison to neighbouring pixels. This prevents noise in the raw data from being accentuated by the iterations but may also lead to loss of data if too large a proportion of the initial dataset is inaccurate. Due to this limitation, the iterative calculations are not adapted for some noisy datasets for which the partial loss of temporal resolution by weighted averaging will be preferable. Monthly averaging is performed as a post-processing step and so may be repeated without the need to recalculate any raw velocity maps. Time series may also be generated from the raw data if monthly averaging is not desirable.

\subsubsection{Georeferencing and plotting}

As a final step, GIV will automatically georeference the velocity grids and save .geotiff files to the user's computer. The toolbox also contains mapping tools that allow for the automatic generation of publication-quality images of the ve-

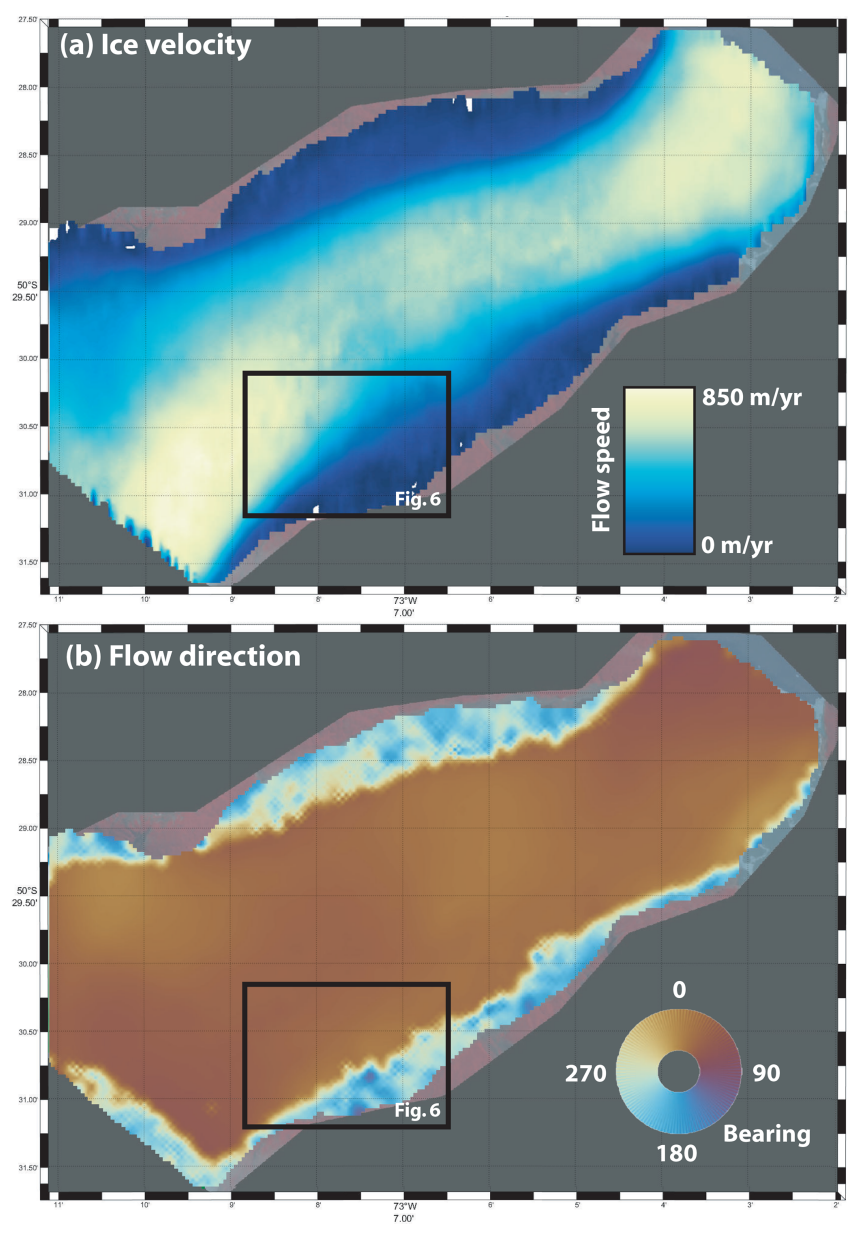

Figure 5. Mean flow velocity $\left(\mathrm{myr}^{-1}\right)$ (a) and direction (degrees) (b) of Glaciar Perito Moreno, Argentina, for the first 3 months of 2020. Figure panels have been automatically generated from GIV, labels have been added, and the colour bars moved.

locity and flow-direction maps (Fig. 5). Flow direction maps are plotted with a circular colourmap, and all colour maps used are colour-blind friendly based on Crameri et al. (2020) and may be modified according to user preferences. In the following section we will examine some case studies of real glaciers and scenarios for which this model may be useful.

\section{Results and examples}

Ice velocity measurements supply essential information for studies of glacier dynamics, thickness, subglacial hydrology, and mass balance. With its GUI-based inputs and potential for parallelization, GIV can calculate a monthly velocity field for any glacier around the world with only a few hours of work. As such, it may also be run alongside field-based expeditions in order to understand the current conditions of the glacier and aid in instrumentation positioning. 


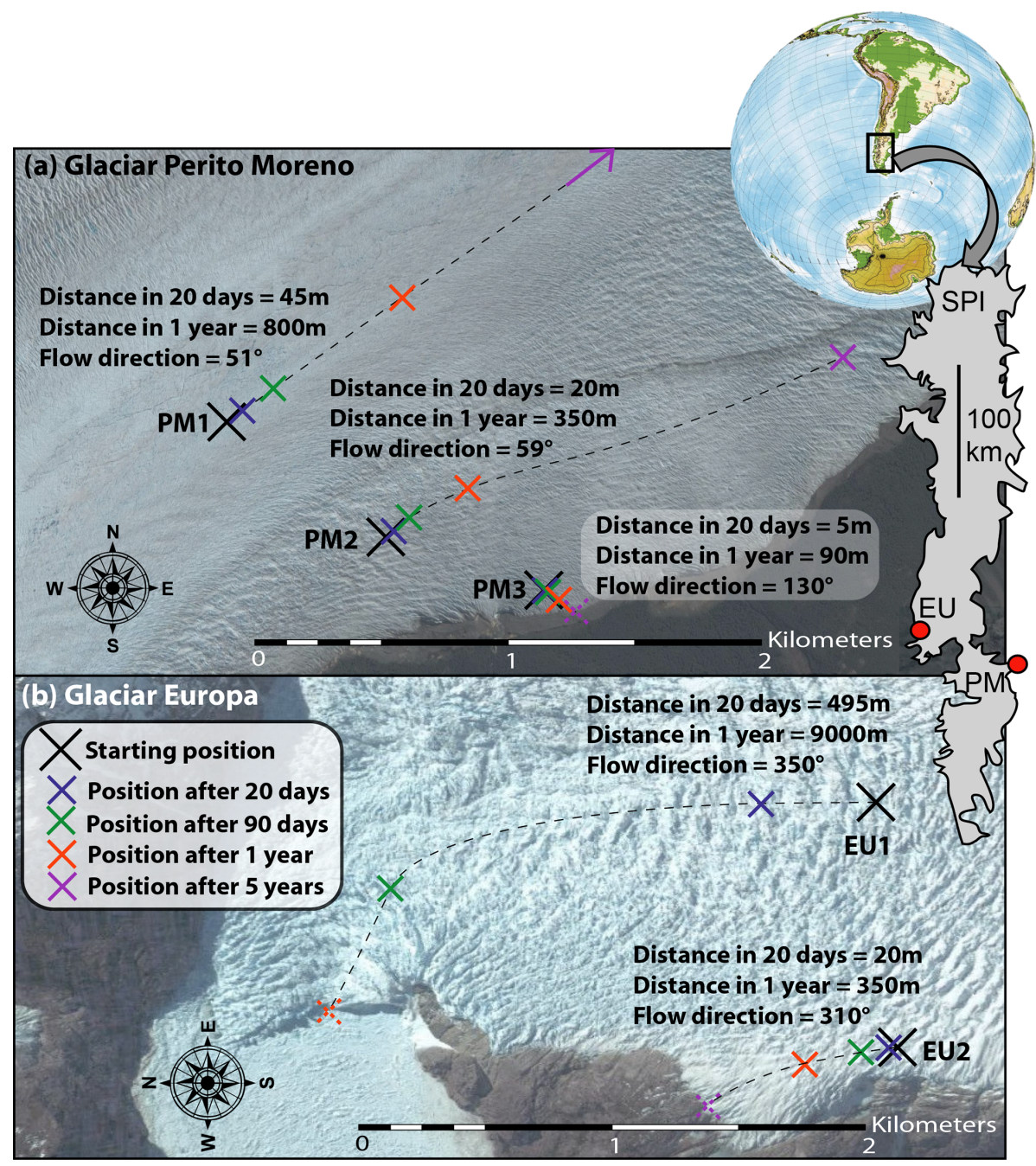

Figure 6. (a) Position of a point on Glaciar Perito Moreno (PM) with the time for three different starting locations within $2 \mathrm{~km}$ of the glacier's southern margin. At PM1, ice speeds reach $800 \mathrm{~m} \mathrm{yr}^{-1}$, and any equipment will be rapidly displaced. At PM3 ice-flow speeds are $<100 \mathrm{~m} \mathrm{yr}^{-1}$ and oriented towards the valley edge. (b) Identical plot for two points on Glaciar Europa (EU). Any equipment installed at EU1 will be displaced several kilometres and lost to calving in less than 6 months. The inlay shows an outline of the Southern Patagonian Icefield (SPI) with the locations of the two glaciers. Imagery (C) Google Earth.

We present four case studies. The first is of Glaciar Perito Moreno $\left(50.48^{\circ} \mathrm{S}, 73.11^{\circ} \mathrm{W}\right)$, where we use GIV to determine the displacement of automated ablation stakes in conjunction with fieldwork in Spring 2020. The second is Glacier d'Argentière $\left(45.95^{\circ} \mathrm{N}, 06.97^{\circ} \mathrm{E}\right)$, a small and wellstudied valley glacier located in the French Alps. The third is Vavilov Ice Cap $\left(79.32^{\circ} \mathrm{N}, 94.34^{\circ} \mathrm{E}\right)$, located on October Revolution Island in the Arctic Ocean off the mainland Russian coast, whose western outlet glacier is now surging. Here we evaluate GIV against published results (Zheng et al., 2019b) using another image-based ice velocity tool, CARST (Zheng et al., 2019a). Finally, we compute ice-flow velocities across the glaciers on Volcán Chimborazo $\left(01.45^{\circ} \mathrm{S}\right.$, $78.82^{\circ} \mathrm{W}$ ) in Ecuador.

\subsection{Field campaign support: Glaciar Perito Moreno and the Southern Patagonian Icefield}

A team from the University of Minnesota installed three automated weather stations and three automated ablation stakes near the southern flank of Glaciar Perito Moreno in order to better understand the local conditions of this glacier and construct temperature-index and energy-balance models for glacier ablation. We installed the automated ablation stakes, based on designs by Wickert (2014) and Wickert et al. (2019) and tested by Saberi et al. (2019) and Armstrong and Anderson (2020), for $20 \mathrm{~d}$ between 23 February and 14 March, 2020. In slow-moving glaciers, ice flow may be largely neglected when considering equipment recovery. In rapidly flowing glaciers such as Perito Moreno, however, it may be 


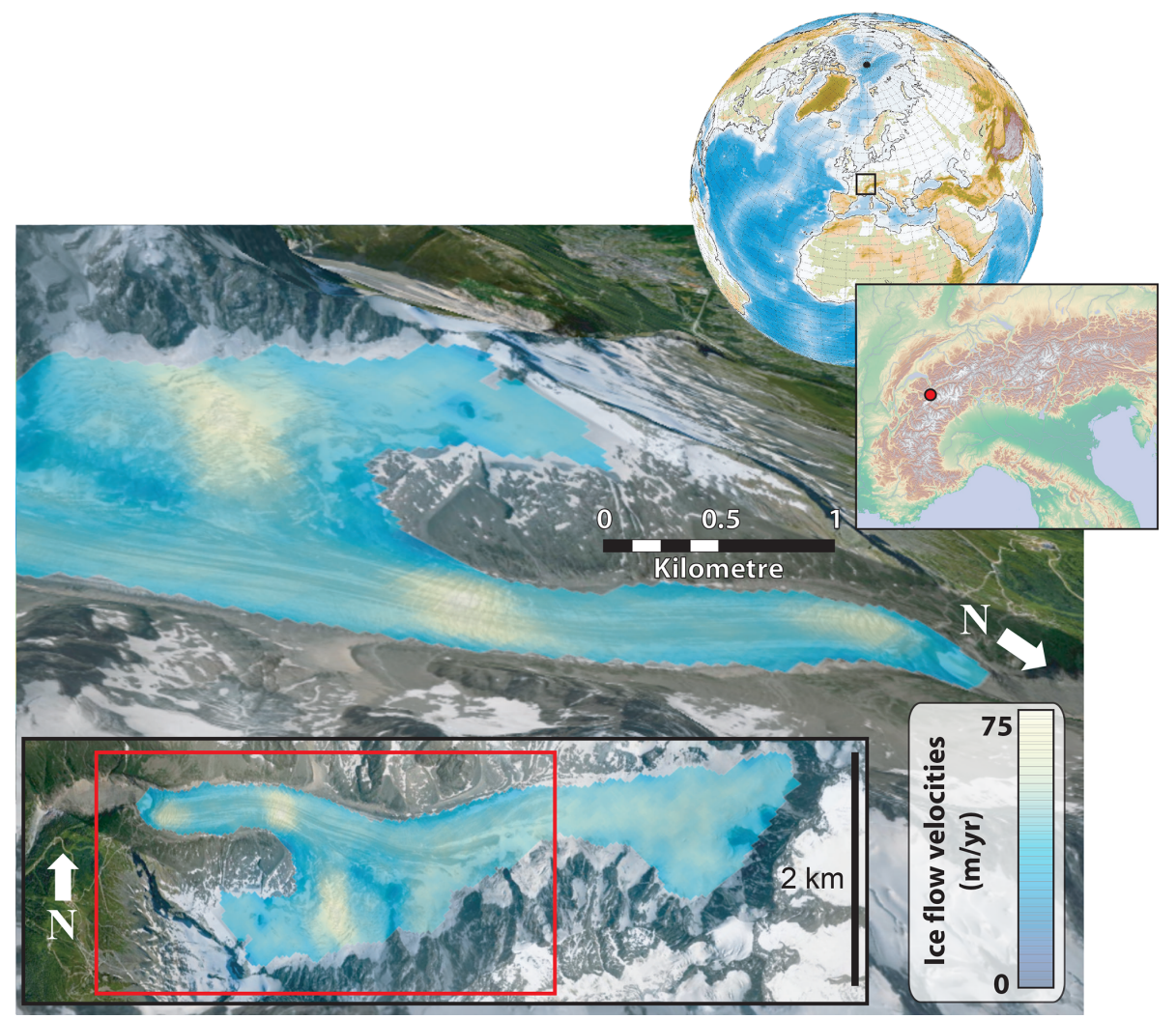

Figure 7. Perspective view of mean flow velocities of Glacier d'Argentière, France, over the period March 2019-March 2020. Imagery is from (C) Google Earth, and scale is for near margin of glacier.

relevant to consider the movement of the glacier when planning equipment recovery. This is particularly relevant where intense crevassing makes both access and visibility difficult. Figure 6 shows how different positioning decisions may influence ease of recovery: ablation stakes installed in position PM1 will move tens of metres towards the glacier calving front in less than a month, whereas stakes in position PM3 will move less than $5 \mathrm{~m}$ towards the glacier flank. In our survey, stakes were installed around position PM3 for ease of access.

Figure $6 \mathrm{~b}$ also presents the case of Glaciar Europa, which drains the adjacent portion of the Southern Patagonian Icefield in Chile. We also derived the mean velocity field of this glacier over the past 3 years using Sentinel-2 imagery (195 image pairs). GIV velocity measurements reveal that the central portion of Glaciar Europa at its outlet flows nearly $10000 \mathrm{~m} \mathrm{yr}^{-1}$. If an ablation stake were installed in this area (point EU1), it would be displaced almost half a kilometre over the course of a $20 \mathrm{~d}$ survey. If it were instead placed at an alternative location $1 \mathrm{~km}$ to the west (EU2), it would be displaced only $20 \mathrm{~m}$ in the same time period. This is an extreme case, and the flow speeds of most glaciers are orders of magnitude slower, but it showcases the potential importance of deriving glacier surface velocity fields for the success of a glaciological field campaign.

\subsection{Valley-glacier velocity distribution: Glacier d'Argentière}

In order to evaluate the effectiveness of GIV on smaller glaciers, we calculate a velocity field for a well-studied valley glacier in the Mont Blanc massif, Glacier d'Argentière (Benoit et al., 2015). We download 1-year worth of Sentinel2 data (March 2019-March 2020), containing over 1000 image pairs. These images are then used to derive a $25 \mathrm{~m}$ resolution mean ice velocity map, shown in Fig. 7. The sparsity of features transverse to flow direction on Glacier d'Argentière make it difficult for feature-tracking methods to calculate velocities. Nevertheless, the resulting flow-velocity map is comparable to those derived using a SPOT satellite image pair from 2003 (Berthier et al., 2005; Rabatel et al., 2018), synthetic-aperture radar (SAR), and groundbased photogrammetry (Benoit et al., 2015) and a different feature-tracking routine based on a modified version of ampcor (Millan et al., 2019). The velocity map highlights accelerated ice flow at the terminus icefall and on the steep tributary glacier to the south-west of the main trunk (Fig. 7). Maintrunk velocities are on the order of $45-70 \mathrm{~m} \mathrm{yr}^{-1}$, slightly slower than SPOT values from Berthier et al. (2005) but in line with values from Benoit et al. (2015). Our values represent the mean over an entire year, including the slower winter 


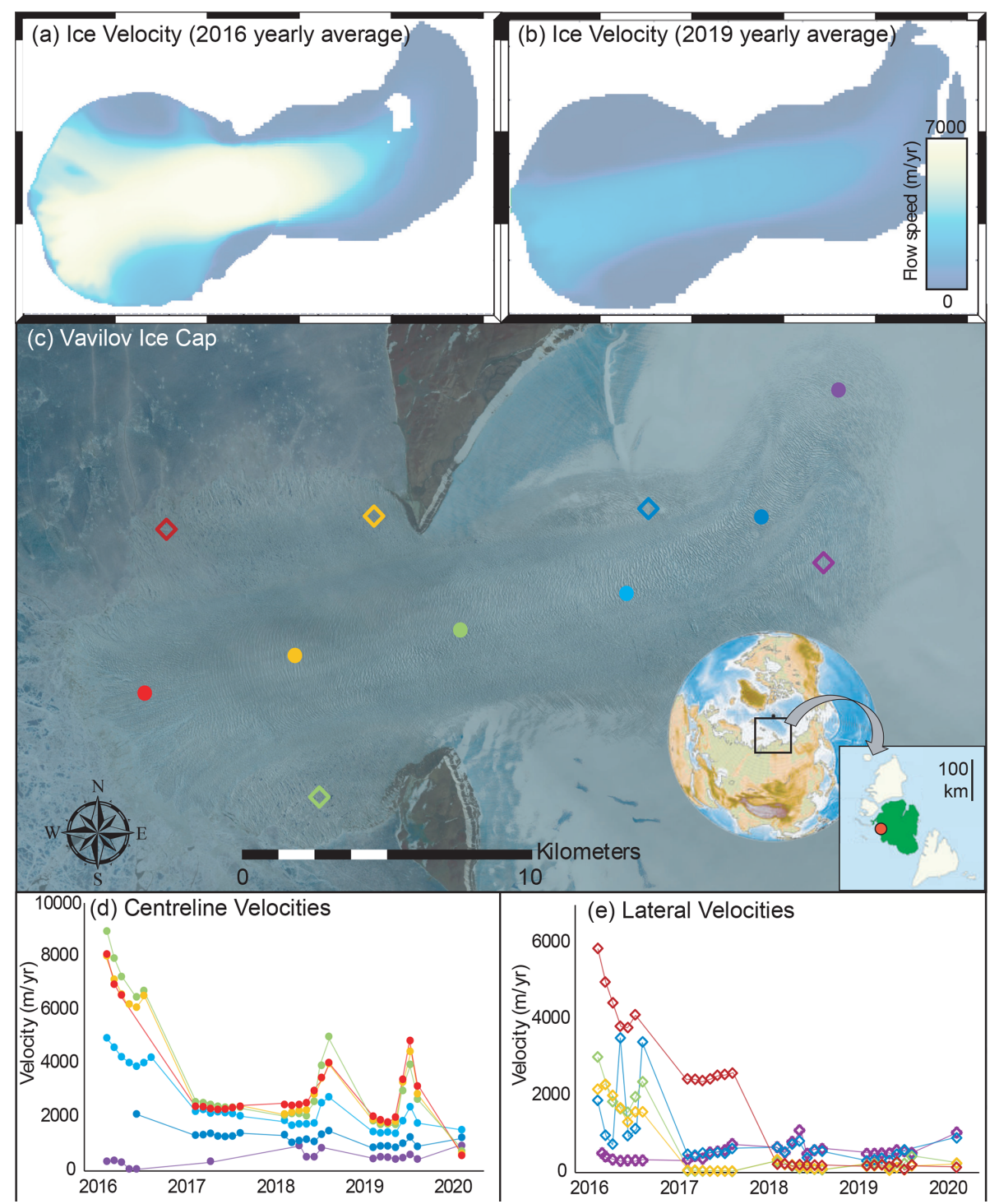

Figure 8. (a, b) $100 \mathrm{~m}$ resolution annual mean velocities for the western outlet glacier of Vavilov Ice Cap. (c) A 2019 Sentinel-2 image showing the main features of this outlet and the locations used to derive monthly time series. (d, e) Monthly resolution velocity time series along the glacier centreline and flanks using Sentinel-2 imagery.

velocities not captured by Berthier et al. (2005). It is also possible that glacier thinning has reduced its flow velocity, but our data are not sufficient to evaluate this.

\subsection{Vavilov Ice Cap dynamics}

Arctic land-ice melt, including both the Greenland Ice Sheet and all Arctic glaciers, has contributed more than $20 \mathrm{~mm}$ to global sea level rise since the 1970s (Box et al., 2018). Most of these large glaciers remain remote and difficult to access, and high spatial and temporal resolution surface velocity maps provide one important tool to assess their response to changing environmental conditions.
Vavilov Ice Cap is a $1700 \mathrm{~km}^{3}$ glacier on October Revolution Island in the Severnaya Zemlya archipelago located in the Russian high arctic (Bassford et al., 2006). Until the 2010s, Vavilov Ice Cap exhibited surface velocities of only a few tens of metres per year, typical of many cold-based high-arctic ice masses. In 2013, a large portion of the marineterminating western flank surged, with the ice front reaching more than $10 \mathrm{~km}$ beyond its prior grounding line by 2016 (Willis et al., 2018; Zheng et al., 2019b). This sudden shift in ice behaviour was not accompanied by any dramatic climatic shift, and the exact triggers are a matter of active debate (Willis et al., 2018, and references therein). Willis et al. (2018) proposed that the dramatic acceleration is related to the glacier overriding weak marine sediments 

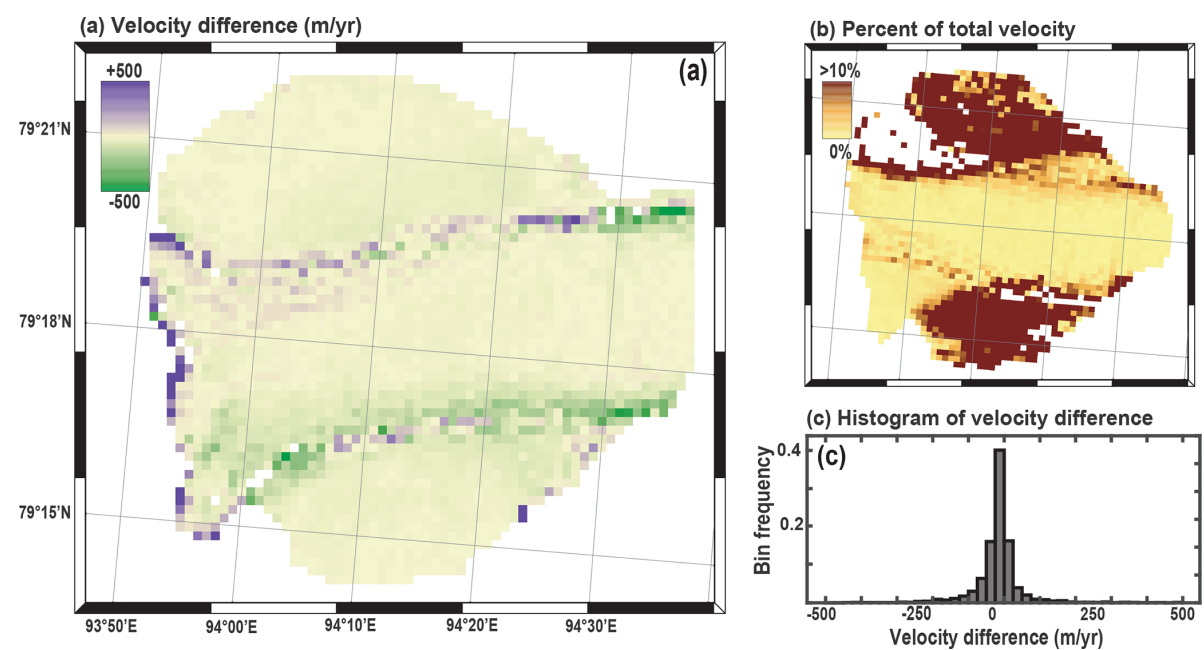

(c) Histogram of velocity difference

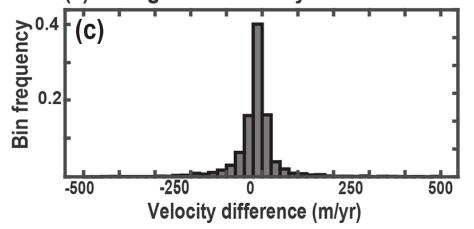

Figure 9. Comparison between the velocity maps of Zheng et al. (2019b) for Vavilov Ice Cap (Pair037_20170506_20170522) and results from GIV (May 2017 average). (a) Difference map, corresponding to the velocity minus GIV velocity from Zheng et al. (2019b), (b) percentage of the total velocity this difference represents (absolute value of the difference shown in (a) divided by GIV velocity), and (c) histogram of the difference values. The mean difference between the two velocity maps is less than $20 \mathrm{~m} \mathrm{yr}^{-1}$ or less than $1 \%$ of the total velocity for much of the area.

in the Kara Sea, which can deform easily and substantially increase ice velocity. The glacier margin is also no longer frozen to bedrock, leading to the associated removal of resistive stresses at the ice front (Willis et al., 2018). Rapid ice flow initiates a set of internal feedbacks to further increase ice velocity, including strain softening of the ice itself, shear heating that produces meltwater capable of reducing the effective normal stress of the ice and hence its friction against the bed, and potential infiltration of this water into the bed material, increasing its deformability (Sevestre and Benn, 2015; Willis et al., 2018, and references therein). With no direct data on subglacial conditions prior to or during the surge, the exact processes involved remain difficult to determine. We may, however, monitor surface ice velocities to examine the ongoing changes in ice kinematics.

Optical satellite imagery from Vavilov Ice Cap is available only for summer months (March to September) due to darkness during the high-latitude boreal winter. We use GIV to derive a $100 \mathrm{~m}$ resolution ice velocity map of a $365 \mathrm{~km}^{2}$ area of the western flank of the glacier using all Sentinel-2 imagery from 2016 to 2020 . Figure $8 \mathrm{a}$ and b present two average yearly velocity maps for the apex of the surge in 2016 and in 2019. Figure $8 \mathrm{~d}$ and e presents time series of monthly velocities over the period from March 2016 to March 2020 at the locations shown in Fig. 8c.

Velocities of the centreline points converge over the time period considered: although the velocities near the ice front decrease from the 2016 peak (red, orange, and green circles), velocities of regions most distant from the coast show a steady increase (purple points). The central portion of this newly formed outlet glacier shows distinct late-summer accelerations in both 2018 and 2019, reaching around double its spring and early summer rates and rapidly decaying (Fig. 7d). Within the newly formed western frontal lobe, extruded beyond the prior grounding line, flow has concentrated into a single branch with well-developed shear margins separating a central region with rapid ice flow from slow-moving lateral portions of the glacier (Zheng et al., 2019b).

Extraction of high-resolution ice velocities in this region using GIV confirms the findings of Willis et al. (2018) and Zheng et al. (2019b) that the western portion of Vavilov has entered into a new fast-flow regime. The late summer velocity peaks in both 2018 and 2019 may shed some light on the driving forces behind this acceleration if associated changes in climatic, ice surface, or ice basal conditions are identified. Ongoing monitoring will help to determine whether a similar peak occurs in subsequent years, and this can be performed in near real time using GIV.

We compare our GIV-derived results against a velocity map of the front of the western outlet glacier generated by Zheng et al. (2019b) using CARST (Zheng et al., 2019a). Zheng et al. (2019b) generated their velocity map based on a single Landsat 8 pair dated 6 and 22 May 2017. We compared the ice-surface velocity magnitude calculated from this pair to the May 2017 average velocity map generated from Sentinel-2 imagery using GIV through the approach described above. We georeferenced the two velocity maps using the glacier margins and other notable features. The difference map (Fig. 9a) displays the highest amplitude anomalies along the margins of the central high-velocity band. Differences between the GIV- and CARST-derived velocity maps are normally distributed, with a mean difference of $-16 \mathrm{~m} \mathrm{yr}^{-1}$ (Fig. 9c). This mean difference is $\leq 1 \%$ of the speed across the majority of the glacier surface (Fig. 9b). In 
this region of the glacier surface, the annual variability in icesurface velocities is on the order of several hundred metres per year (Fig. 8d and e), and this difference may result from the slightly different dates covered or differing image resolutions (10 m for Sentinel-2 compared to 15-30 m for Landsat). The high-magnitude difference bands on either side of the fast-moving central region may also result in whole or in part from georeferencing errors in GIV, in CARST, or in our work to georeference these two velocity maps to one another.

\subsection{Ice velocity of a small tropical glacier: Chimborazo}

Many tropical glaciers have limited to no ice-flow data from direct field measurements (Thompson et al., 2011). These are important water sources to millions of people (Bury et al., 2011; Chevallier et al., 2011; La Frenierre and Mark, 2017). Vergara et al. (2007) estimated the economic cost of glacier retreat on water use to be in the hundreds of millions of US dollars and the impact on Peru's electrical utility to be $\sim 1.5$ billion. High-resolution estimates of ice velocity provide information on glacier state and can contribute to practical decision-making in the tropical Andes.

Chimborazo is a $6268 \mathrm{~m}$ high stratovolcano in Ecuador covered with 17 glaciers. On Chimborazo's north-eastern flank, glacier meltwater drives nearly all of the discharge variability, and the disappearance of the prominent Reschreiter Glacier could decrease the discharge of the watershed's outlet stream by up to $50 \%$ (Saberi et al., 2019). Due to its high elevation and steep slopes that are unstable in regions of recent ice retreat, the glaciers on Chimborazo are difficult to survey (Saberi et al., 2019). No field measurements of glacier surface velocity have been conducted.

Chimborazo poses challenges to feature-tracking-based ice velocimetry as its glaciers are small, regularly featurepoor or snow covered, very slow moving, and cloud covered for large parts of the year. The velocity limitations are mitigated by using only images with large temporal separation (acquisition dates more than 6 months apart). GIV is also well suited for extracting velocities from partially clouded imagery. We run GIV on the full Sentinel-2 dataset, which is comprised of 91 individual partially or fully cloud-free images. These were cropped to Chimborazo, resulting in 3062 image pairs separated by at least 6 months. Resultant ice velocities for each pair were corrected for the mean displacement of a stable, non-glaciated region surrounding the glaciers. Results are shown in Fig. 10.

\section{Discussion and conclusions}

These four examples underline GIV's flexibility, ease of use, and ability to rapidly process large datasets for calculating ice velocities in a range of environments. Most regular laptop and desktop computers now include at least four cores, which GIV uses to speed up calculations by a factor of 2

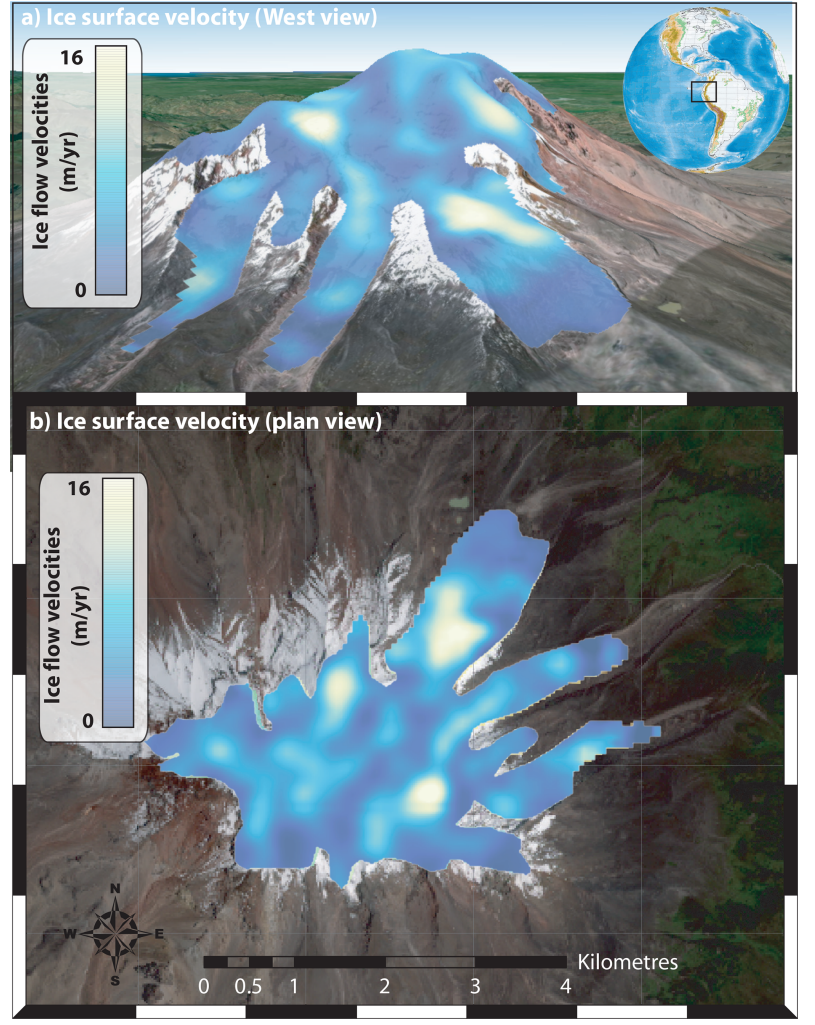

Figure 10. Ice-surface-velocity map for the Chimborazo glaciers calculated with GIV. Imagery (C) Google Earth and Sentinel-2.

or more (Fig. 3). This makes velocity-field calculations with hundreds to tens of thousands of image pairs practical on regular computers. The inclusion of "temporal oversampling" allows much larger datasets to be generated than via simple consecutive image comparison; a dataset of 100 images may in fact include several thousand usable image pairs. We combine methodological advances in feature tracking and image processing from both geoscience and engineering toolboxes and develop new filtering techniques to improve the quality of the final surface-velocity maps. GIV provides a rapid and easy-to-use interface (shown in Fig. 11) and a user manual and may also be of use to communities who would not generally be involved with glacier remote sensing (Van Wyk de Vries, 2021a, b).

GIV is easily learned and is not computationally timeconsuming, and the results derived with it are easy to reproduce. GIV allows users to modify image-processing and feature-tracking parameters based on their expert knowledge of particular glaciers without the need for specific computational knowledge. GIV may be run either directly through MATLAB functions, through a MATLAB graphical user interface (Van Wyk de Vries, 2021a), or as an independent desktop app that may be run with no MATLAB license (Van Wyk de Vries, 2021b). GIV has been tested and successfully run on Windows, Mac, and Linux operating systems. 


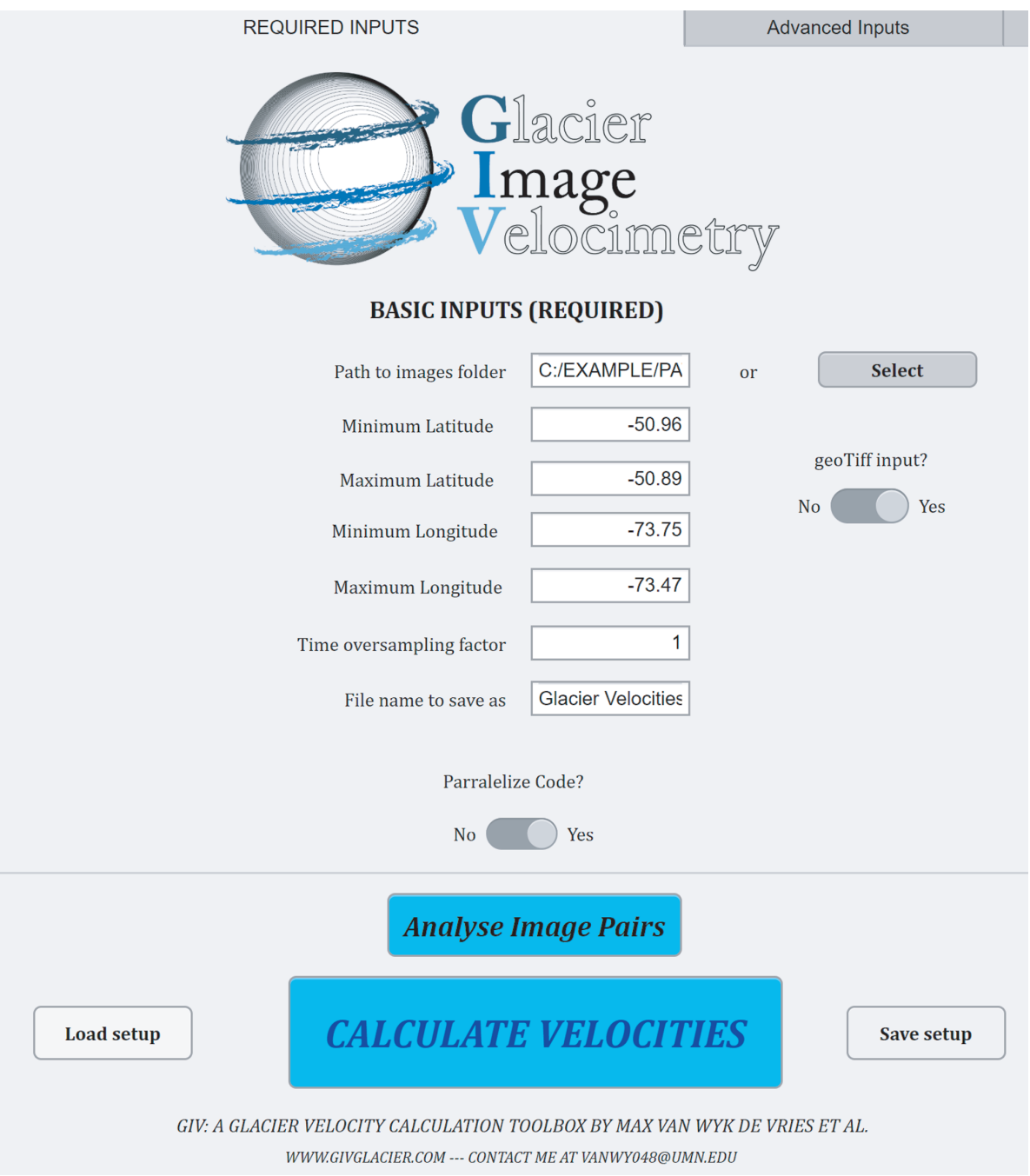

Figure 11. Main graphical user interface for GIV showing the main input fields. This interface may either be run through MATLAB or as an independent desktop app with no licensing requirements.

In summary, GIV is a versatile, GUI-based, and fully parallelized toolbox that enables the rapid calculation of glacier velocity fields from satellite imagery. GIV builds upon recent improvements in optical satellite imagery availability and resolution to extract high temporal and high spatial resolution velocity maps, and it uses novel and pre-existing filters to optimize the quality of these velocity maps. GIV has been successfully tested on a wide range of environments, including small valley glaciers (Glacier d'Argentière, France), tropical glaciers (Volcán Chimborazo, Ecuador), and large outlet glaciers (Glaciar Perito Moreno, Argentina, and outflow from Vavilov Ice Cap, Russia). We show that ice velocity datasets are versatile and may be used to complement field campaigns and study the dynamics of large and small glaciers. Source code and pre-compiled binary executables for GIV are available from Van Wyk de Vries (2021a) and Van Wyk de Vries (2021b).
Code availability. MATLAB code for GIV may be downloaded from https://github.com/MaxVWDV/glacier-image-velocimetry (last access: 24 April 2021, Van Wyk de Vries, 2021a). The GIV stand-alone app may be downloaded from https://github.com/MaxVWDV/glacier-image-velocimetry-app (last access: 24 April 2021, Van Wyk de Vries, 2021b). Both include a user manual and an example dataset.

Data availability. All the velocity maps presented in this paper are derived from Sentinel-2 imagery, which may be freely accessed online. Specific example datasets and information on how to reproduce our results are included in the GIV GitHub repository and user manual. 
Supplement. The supplement related to this article is available online at: https://doi.org/10.5194/tc-15-2115-2021-supplement.

Author contributions. MVWdV and ADW planned the project. MVWdV wrote the code and ran the examples. MVWdV and ADW wrote and edited the manuscript.

Competing interests. The authors declare that they have no conflict of interest.

Acknowledgements. Maximillian Van Wyk de Vries was supported by a University of Minnesota College of Science and Engineering fellowship. Ben Popken assisted with early testing of GIV. Emi Ito, Kelly MacGregor, Jeff La Frenierre, Matias Romero, Shanti B. Penprase, Jabari Jones, and Kerry L. Callaghan provided comments on this manuscript. David Carchipulla helped improve imagedownload workflows. Conversations about feature tracking with Whyjay Zheng, Shashank Bhushan, Will Kochtitzky, and David Shean have helped refine the ideas in this paper and in GIV's code. We acknowledge Ted Scambos and two anonymous referees for thoughtful reviews which improved both the manuscript and the associated toolbox. We further thank editor Harry Zekollari for detailed suggestions which were valuable for fine-tuning our text and figures. This material is based upon work supported by the National Science Foundation under grant no. EAR-1714614, coordinated by lead PI Maria Beatrice Magnani.

Financial support. This research has been supported by the United States National Science Foundation (grant no. EAR-1714614).

Review statement. This paper was edited by Harry Zekollari and reviewed by Ted Scambos and two anonymous referees.

\section{References}

Altena, B.: Observing change in glacier flow by using optical satellites, $\mathrm{PhD}$ thesis, available at: https://www.duo.uio.no/handle/ 10852/61747 (last access: 24 April 2021), 2018.

Altena, B., Scambos, T., Fahnestock, M., and Kääb, A.: Extracting recent short-term glacier velocity evolution over southern Alaska and the Yukon from a large collection of Landsat data, The Cryosphere, 13, 795-814, https://doi.org/10.5194/tc13-795-2019, 2019.

Armstrong, W. H. and Anderson, R. S.: Ice-marginal lake hydrology and the seasonal dynamical evolution of Kennicott Glacier, Alaska, J. Glaciol., 66, 699-713, 2020.

Bassford, R. P., Siegert, M. J., Dowdeswell, J. A., Oerlemans, J., Glazovsky, A. F., and Macheret, Y. Y.: Quantifying the Mass Balance of Ice Caps on Severnaya Zemlya, Russian High Arctic. I: Climate and Mass Balance of the Vavilov Ice Cap, Arct. Antarct. Alp. Res., 38, 1-12, https://doi.org/10.1657/15230430(2006)038[0013:QTMBOI]2.0.CO;2, 2006.
Benoit, L., Dehecq, A., Pham, H.-T., Vernier, F., Trouvé, E., Moreau, L., Martin, O., Thom, C., Pierrot-Deseilligny, M., and Briole, P.: Multi-method monitoring of Glacier d'Argentière dynamics, Ann. Glaciol., 56, 118-128, https://doi.org/10.3189/2015AoG70A985, 2015.

Berthier, E., Vadon, H., Baratoux, D., Arnaud, Y., Vincent, C., Feigl, K. L., Rémy, F., and Legrésy, B.: Surface motion of mountain glaciers derived from satellite optical imagery, Remote Sens. Environ., 95, 14-28, https://doi.org/10.1016/j.rse.2004.11.005, 2005.

Bindschadler, R. A. and Scambos, T. A.: Satellite-Image-Derived Velocity Field of an Antarctic Ice Stream, Science, 252, 242246, https://doi.org/10.1126/science.252.5003.242, 1991.

Bottomley, J. T.: Flow of Viscous Materials-A Model Glacier, Nature, 21, 159-159, https://doi.org/10.1038/021159a0, 1879.

Box, J. E., Colgan, W. T., Wouters, B., Burgess, D. O., O’Neel, S., Thomson, L. I., and Mernild, S. H.: Global sea-level contribution from Arctic land ice: 1971-2017, Environ. Res. Lett., 13, 125 012, https://doi.org/10.1088/1748-9326/aaf2ed, 2018.

Buchhave, P.: Particle image velocimetry-status and trends, Exp. Therm. Fluid Sci., 5, 586-604, https://doi.org/10.1016/08941777(92)90016-X, 1992.

Bury, J. T., Mark, B. G., McKenzie, J. M., French, A., Baraer, M., Huh, K. I., Zapata Luyo, M. A., and Gómez López, R. J.: Glacier recession and human vulnerability in the Yanamarey watershed of the Cordillera Blanca, Peru, Climatic Change, 105, 179-206, https://doi.org/10.1007/s10584-010-9870-1, 2011.

Chadwell, C. D.: Reliability analysis for design of stake networks to measure glacier surface velocity, J. Glaciol., 45, 154-164, https://doi.org/10.3189/S0022143000003130, 1999.

Chevallier, P., Pouyaud, B., Suarez, W., and Condom, T.: Climate change threats to environment in the tropical Andes: glaciers and water resources, Reg. Environ. Change, 11, 179187, https://doi.org/10.1007/s10113-010-0177-6, 2011.

Crameri, F., Shephard, G. E., and Heron, P. J.: The misuse of colour in science communication, Nat. Commun., 11, 5444, https://doi.org/10.1038/s41467-020-19160-7, 2020.

Darji, S., Shah, R. D., Oza, S., and Bahuguna, I. M.: InterComparison of Various Feature Tracking Tools Deriving Glacier Ice Velocity, Int. J. Sci. Res. Rev., 7, 422-429, 2018.

Davies, B. J. and Glasser, N. F.: Accelerating shrinkage of Patagonian glaciers from the Little Ice Age $(\sim \mathrm{AD} 1870)$ to 2011, J. Glaciol., 58, 1063-1084, https://doi.org/10.3189/2012JoG12J026, 2012.

Deeley, R. M. and Parr, P. H.: XVI. The Hintereis Glacier, The London, Edinburgh, and Dublin Philosophical Magazine and Journal of Science, 27, 153-176, 1914.

Drusch, M., Del Bello, U., Carlier, S., Colin, O., Fernandez, V., Gascon, F., Hoersch, B., Isola, C., Laberinti, P., Martimort, P., Meygret, A., Spoto, F., Sy, O., Marchese, F., and Bargellini, P.: Sentinel-2: ESA's Optical High-Resolution Mission for GMES Operational Services, Remote Sens. Environ., 120, 25-36, https://doi.org/10.1016/j.rse.2011.11.026, 2012.

Fahnestock, M., Scambos, T., Moon, T., Gardner, A., Haran, T., and Klinger, M.: Rapid large-area mapping of ice flow using Landsat 8, Remote Sens. Environ., 185, 84-94, https://doi.org/10.1016/j.rse.2015.11.023, 2016.

Fitch, A., Kadyrov, A., Christmas, W., and Kittler, J.: Orientation Correlation, in: Procedings of the British Ma- 
chine Vision Conference 2002, pp. 11.1-11.10, British Machine Vision Association, Cardiff, 2-5 September 2002, https://doi.org/10.5244/C.16.11, 2002.

Forbes, J. D.: The Glacier Theory, google-Books-ID: wPoTAAAAQAAJ, 1840.

Forbes, J. D.: XII. Illustrations of the viscous theory of glacier motion. - Part I. Containing experiments on the flow of plastic bodies, and observations on the phenomena of lava streams, Philos. T. R. Soc. Lond., 136, 143-155, https://doi.org/10.1098/rstl.1846.0013, 1846.

Fowler, A.: Weertman, Lliboutry and the development of sliding theory, J. Glaciol., 56, 965-972, https://doi.org/10.3189/002214311796406112, 2010.

Frigo, M. and Johnson, S.: FFTW: an adaptive software architecture for the FFT, in: Proceedings of the 1998 IEEE International Conference on Acoustics, Speech and Signal Processing, ICASSP '98 (Cat. No.98CH36181), vol. 3, pp. 1381-1384, IEEE, Seattle, WA, USA, 15 May 1998, https://doi.org/10.1109/ICASSP.1998.681704, 1998.

Frigo, M. and Johnson, S.: The Design and Implementation of FFTW3, P. IEEE, 93, 216-231, https://doi.org/10.1109/JPROC.2004.840301, 2005.

Gardner, A., Fahnestock, M., and Scambos, T.: ITS_LIVE Regional Glacier and Ice Sheet Surface Velocities, National Snow and Ice Data Center, https://doi.org/10.5067/6II6VW8LLWJ7, 2020.

Gardner, A. S., Moholdt, G., Scambos, T., Fahnstock, M., Ligtenberg, S., van den Broeke, M., and Nilsson, J.: Increased West Antarctic and unchanged East Antarctic ice discharge over the last 7 years, The Cryosphere, 12, 521-547, https://doi.org/10.5194/tc-12-521-2018, 2018.

Grant, I.: Particle image velocimetry: A review, P. I. Mech. Eng. C-J. Mec., 211, 55-76, https://doi.org/10.1243/0954406971521665, 1997.

Heid, T. and Kääb, A.: Evaluation of existing image matching methods for deriving glacier surface displacements globally from optical satellite imagery, Remote Sens. Environ., 118, 339-355, https://doi.org/10.1016/j.rse.2011.11.024, 2012a.

Heid, T. and Kääb, A.: Repeat optical satellite images reveal widespread and long term decrease in land-terminating glacier speeds, The Cryosphere, 6, 467-478, https://doi.org/10.5194/tc6-467-2012, 2012b.

Hooke, R. L., Calla, P., Holmlund, P., Nilsson, M., and Stroeven, A.: A 3 Year Record of Seasonal Variations in Surface Velocity, StorglaciÄren, Sweden, J. Glaciol., 35, 235-247, https://doi.org/10.3189/S0022143000004561, 1989.

How, P., Hulton, N. R. J., Buie, L., and Benn, D. I.: PyTrx: A Python-Based Monoscopic Terrestrial Photogrammetry Toolset for Glaciology, Front. Earth Sci., 8, https://doi.org/10.3389/feart.2020.00021, 2020.

Howat, I. M., Porter, C., Smith, B. E., Noh, M.-J., and Morin, P.: The Reference Elevation Model of Antarctica, The Cryosphere, 13, 665-674, https://doi.org/10.5194/tc-13-665-2019, 2019.

James, M. R., How, P., and Wynn, P. M.: Pointcatcher software: analysis of glacial time-lapse photography and integration with multitemporal digital elevation models, J. Glaciol., 62, 159-169, https://doi.org/10.1017/jog.2016.27, 2016.

Jawak, S. D., Kumar, S., Luis, A. J., Bartanwala, M., Tummala, S., and Pandey, A. C.: Evaluation of Geospatial Tools for Generating Accurate Glacier Velocity Maps from Optical Remote Sensing
Data, Proceedings, 2, 341, https://doi.org/10.3390/ecrs-2-05154, 2018.

Kamb, B. and LaChapelle, E.: Direct Observation of the Mechanism of Glacier Sliding Over Bedrock, J. Glaciol., 5, 159-172, https://doi.org/10.3189/S0022143000028756, 1964.

Kääb, A. and Vollmer, M.: Surface Geometry, Thickness Changes and Flow Fields on Creeping Mountain Permafrost: Automatic Extraction by Digital Image Analysis, Permafrost Periglac., 11, 315-326, https://doi.org/10.1002/10991530(200012)11:4<315::AID-PPP365>3.0.CO;2-J, 2000.

Kääb, A., Winsvold, S. H., Altena, B., Nuth, C., Nagler, T., and Wuite, J.: Glacier Remote Sensing Using Sentinel-2. Part I: Radiometric and Geometric Performance, and Application to Ice Velocity, Remote Sens.-bASEL, 8, 598, https://doi.org/10.3390/rs8070598, 2016.

Kobayashi, T. and Otsu, N.: Image Feature Extraction Using Gradient Local Auto-Correlations, in: Computer Vision - ECCV 2008, edited by: Forsyth, D., Torr, P., and Zisserman, A., Lecture Notes in Computer Science, vol. 5302, Springer, Berlin, Heidelberg, https://doi.org/10.1007/978-3-540-88682-2_27, 2008.

La Frenierre, J. and Mark, B. G.: Detecting Patterns of Climate Change at Volcán Chimborazo, Ecuador, by Integrating Instrumental Data, Public Observations, and Glacier Change Analysis, Ann. Am. Assoc. Geogr., 107, 979-997, https://doi.org/10.1080/24694452.2016.1270185, 2017.

Lee, R. M., Yue, H., Rappel, W.-J., and Losert, W.: Data from: Inferring single cell behavior from large-scale epithelial sheet migration patterns, Digital Repository at the University of Maryland, https://doi.org/10.13016/M2855R, 2017.

Leprince, S., Ayoub, F., Klinger, Y., and Avouac, J.-P.: Co-Registration of Optically Sensed Images and Correlation (COSI-Corr): an operational methodology for ground deformation measurements, in: 2007 IEEE International Geoscience and Remote Sensing Symposium, pp. 1943-1946, IEEE, Barcelona, Spain, 23-28 July 2007, https://doi.org/10.1109/IGARSS.2007.4423207, 2007a.

Leprince, S., Barbot, S., Ayoub, F., and Avouac, J.-P.: Automatic and Precise Orthorectification, Coregistration, and Subpixel Correlation of Satellite Images, Application to Ground Deformation Measurements, IEEE T. Geosci. Remote, 45, 1529-1558, https://doi.org/10.1109/TGRS.2006.888937, 2007b.

Mair, D., Willis, I., Fischer, U. H., Hubbard, B., Nienow, P., and Hubbard, A.: Hydrological controls on patterns of surface, internal and basal motion during three "spring events": Haut Glacier d'Arolla, Switzerland, J. Glaciol., 49, 555-567, https://doi.org/10.3189/172756503781830467, 2003.

Meier, M. F. and Tangborn, W. V.: Net Budget and Flow of South Cascade Glacier, Washington, J. Glaciol., 5, 547-566, https://doi.org/10.3189/S0022143000018608, 1965.

Messerli, A. and Grinsted, A.: Image georectification and feature tracking toolbox: ImGRAFT, Geosci. Instrum. Method. Data Syst., 4, 23-34, https://doi.org/10.5194/gi-4-23-2015, 2015.

Millan, R.: Ice thickness and bed elevation of the Patagonian Icefields [Data set], Dryad, https://doi.org/10.7280/d11q17, 2019.

Millan, R., Mouginot, J., Rabatel, A., Jeong, S., Cusicanqui, D., Derkacheva, A., and Chekki, M.: Mapping Surface Flow Velocity of Glaciers at Regional Scale Using a Multiple Sensors Approach, Remote Sens.-Basel, 11, 2498, https://doi.org/10.3390/rs11212498, 2019. 
Minchew, B. M., Simons, M., Riel, B., and Milillo, P.: Tidally induced variations in vertical and horizontal motion on Rutford Ice Stream, West Antarctica, inferred from remotely sensed observations, J. Geophys. Res.-Earth, 122, 167-190, https://doi.org/10.1002/2016JF003971, 2017.

Mote, T. L.: Greenland surface melt trends 1973-2007: Evidence of a large increase in 2007, J. Geophys. Res., 34, L22507, https://doi.org/10.1029/2007GL031976, 2007.

Mouginot, J. and Rignot, E.: Ice motion of the Patagonian Icefields of South America: 1984-2014, J. Geophys. Res., 42, 1441-1449, https://doi.org/10.1002/2014GL062661, 2015.

Nagy, T. and Andreassen, L. M.: Glacier surface velocity mapping with Sentinel-2 imagery in Norway, Norwegian water resources and energy directorate (NVE), 2019.

Nagy, T., Andreassen, L. M., Duller, R. A., and Gonzalez, P. J.: SenDiT: The Sentinel-2 Displacement Toolbox with Application to Glacier Surface Velocities, Remote Sens.-Basel, 11, 1151, https://doi.org/10.3390/rs11101151, 2019.

Nye, J. F.: The Mechanics of Glacier Flow, J. Glaciol., 2, 82-93, https://doi.org/10.3189/S0022143000033967, 1952.

Nye, J. F.: Glacier sliding without cavitation in a linear viscous approximation, P. Roy. Soc. Lond. A Mat, 315, 381-403, 1970.

Oertel, M. and Süfke, F.: Two-dimensional dambreak wave analysis: particle image velocimetry versus optical flow, J. Hydraul. Res., 58, 326-334, https://doi.org/10.1080/00221686.2019.1579114, 2020.

Pfeffer, W. T., Arendt, A. A., Bliss, A., Bolch, T., Cogley, J. G., Gardner, A. S., Hagen, J.-O., Hock, R., Kaser, G., Kienholz, C., Miles, E. S., Moholdt, G., Mölg, N., Paul, F., Radić, V., Rastner, P., Raup, B. H., Rich, J., Sharp, M. J., and Consortium, T. R.: The Randolph Glacier Inventory: a globally complete inventory of glaciers, J. Glaciol., 60, 537-552, https://doi.org/10.3189/2014JoG13J176, 2014.

Rabatel, A., Sanchez, O., Vincent, C., and Six, D.: Estimation of Glacier Thickness From Surface Mass Balance and Ice Flow Velocities: A Case Study on Argentière Glacier, France, Front. Earth Sci., 6, https://doi.org/10.3389/feart.2018.00112, 2018.

Raffel, M., Willert, C. E., Scarano, F., Kähler, C. J., Wereley, S. T., and Kompenhans, J.: Particle Image Velocimetry: A Practical Guide, Springer, New York, google-Books-ID: wk9UDwAAQBAJ, 2018.

Rignot, E., Mouginot, J., and Scheuchl, B.: Ice Flow of the Antarctic Ice Sheet, Science, 333, 1427-1430, https://doi.org/10.1126/science.1208336, 2011.

Saberi, L., McLaughlin, R. T., Ng, G.-H. C., La Frenierre, J., Wickert, A. D., Baraer, M., Zhi, W., Li, L., and Mark, B. G.: Multiscale temporal variability in meltwater contributions in a tropical glacierized watershed, Hydrol. Earth Syst. Sci., 23, 405-425, https://doi.org/10.5194/hess-23-405-2019, 2019.

Scambos, M. F. T.: Global Land Ice Velocity Extraction from Landsat 8 (GoLIVE) [Data set], NSIDC: National Snow and Ice Data Cente, Boulder, CO, USA, https://doi.org/10.7265/N5ZP442B, 2016.

Scambos, T. A., Dutkiewicz, M. J., Wilson, J. C., and Bindschadler, R. A.: Application of image cross-correlation to the measurement of glacier velocity using satellite image data, Remote Sens. Environ., 42, 177-186, https://doi.org/10.1016/0034-4257(92)90101O, 1992 .
Schwalbe, E. and Maas, H.-G.: The determination of highresolution spatio-temporal glacier motion fields from time-lapse sequences, Earth Surf. Dynam., 5, 861-879, https://doi.org/10.5194/esurf-5-861-2017, 2017.

Sevestre, H. and Benn, D. I.: Climatic and geometric controls on the global distribution of surge-type glaciers: implications for a unifying model of surging, J. Glaciol., 61, 646-662, https://doi.org/10.3189/2015JoG14J136, 2015.

Shean, D.: dshean/vmap: Zenodo DOI release, https://doi.org/10.5281/zenodo.3243479, 2019.

Sneed, W. A. and Hamilton, G. S.: Evolution of melt pond volume on the surface of the Greenland Ice Sheet, J. Geophys. Res., 34, https://doi.org/10.1029/2006GL028697, 2007.

Stearns, L. A., Smith, B. E., and Hamilton, G. S.: Increased flow speed on a large East Antarctic outlet glacier caused by subglacial floods, Nat. Geosci., 1, 827-831, https://doi.org/10.1038/ngeo356, 2008.

Stocker, T. F., Qin, D., Plattner, G.-K., Tignor, M., Allen, S. K., Boschung, J., Nauels, A., Xia, Y., Bex, V., and Midgley, P. M.: Climate change 2013: The physical science basis, Contribution of working group I to the fifth assessment report of the intergovernmental panel on climate change, 1535, Cambridge University Press Cambridge, UK and New York, NY, USA, 2013.

Sveen, J. K.: An introduction to MatPIV v. 1.6.1, Matematisk Institutt, Universitetet i Oslo, available at: https://www.duo.uio.no/ handle/10852/10196 (last access: 24 April 2021), 2004.

Sveen, J. K. and Cowen, E. A.: Quantitative imaging techniques and their application to wavy flows, in: PIV and Water Waves, vol. 9, in: Advances in Coastal and Ocean Engineering, 1-49, https://doi.org/10.1142/9789812796615_0001, 2004.

Thielicke, W. and Stamhuis, E.: PIVlab - Towards User-friendly, Affordable and Accurate Digital Particle Image Velocimetry in MATLAB, Journal of Open Research Software, 2, e30, https://doi.org/10.5334/jors.bl, 2014.

Thompson, L. G., Mosley-Thompson, E., Davis, M. E., and Brecher, H. H.: Tropical glaciers, recorders and indicators of climate change, are disappearing globally, Ann. Glaciol., 52, 23-34, https://doi.org/10.3189/172756411799096231, 2011.

van de Wal, R. S. W., Boot, W., Broeke, M. R. v. d., Smeets, C. J. P. P., Reijmer, C. H., Donker, J. J. A., and Oerlemans, J.: Large and Rapid Melt-Induced Velocity Changes in the Ablation Zone of the Greenland Ice Sheet, Science, 321, 111-113, https://doi.org/10.1126/science.1158540, 2008.

Van Wyk de Vries, M.: Glacier Image Velocimetry (GIV), Zenodo, https://doi.org/10.5281/zenodo.4624831, 2021a.

Van Wyk de Vries, M.: Glacier Image Velocimetry (GIV) app, https://doi.org/10.5281/zenodo.4147589, 2021b.

Vergara, W., Deeb, A., Valencia, A., Bradley, R., Francou, B., Zarzar, A., Grünwaldt, A., and Haeussling, S.: Economic impacts of rapid glacier retreat in the Andes, Eos T. Am. Geophys. Un., 88, 261-264, https://doi.org/10.1029/2007EO250001, 2007.

Weertman, J.: On the Sliding of Glaciers, J. Glaciol., 3, 33-38, https://doi.org/10.3189/S0022143000024709, 1957.

Wickert, A. D.: The ALog: Inexpensive, Open-Source, Automated Data Collection in the Field, The Bulletin of the Ecological Society of America, 95, 166-176, https://doi.org/10.1890/00129623-95.2.68, 2014.

Wickert, A. D., Sandell, C. T., Schulz, B., and Ng, G.-H. C.: Open-source Arduino-compatible data loggers designed 
for field research, Hydrol. Earth Syst. Sci., 23, 2065-2076, https://doi.org/10.5194/hess-23-2065-2019, 2019.

Willis, M. J., Zheng, W., Durkin, W. J., Pritchard, M. E., Ramage, J. M., Dowdeswell, J. A., Benham, T. J., Bassford, R. P., Stearns, L. A., Glazovsky, A. F., Macheret, Y. Y., and Porter, C. C.: Massive destabilization of an Arctic ice cap, Earth Planet. Sc. Lett., 502, 146-155, https://doi.org/10.1016/j.epsl.2018.08.049, 2018.

Zheng, W., Pritchard, M. E., Willis, M. J., Tepes, P., Gourmelen, N., Benham, T. J., and Dowdeswell, J. A.: Accelerating glacier mass loss on Franz Josef Land, Russian Arctic, Remote Sens. Environ., 211, 357-375, https://doi.org/10.1016/j.rse.2018.04.004, 2018.
Zheng, W., Durkin, W. J., Melkonian, A. K., and Pritchard, M. E.: Cryosphere And Remote Sensing Toolkit (CARST) v1.0.1, Zenodo, https://doi.org/10.5281/zenodo.3475693, 2019a.

Zheng, W., Pritchard, M. E., Willis, M. J., and Stearns, L. A.: The Possible Transition From Glacial Surge to Ice Stream on Vavilov Ice Cap, J. Geophys. Res., 46, 13892-13902, https://doi.org/10.1029/2019GL084948, 2019b. 